\title{
Decreasing Incidence of Gestational Choriocarcinoma in Enugu State University of Science and Technology Teaching Hospital, South- East Nigeria: A 7-Year Review
}

\author{
Nweze Sylvester Onuegbunam ${ }^{1}$, Ezenwaeze Malachy Nwaeze ${ }^{2}$, \\ Igwe Samuel Agina ${ }^{3}$ \\ ${ }^{1}$ Department of Obstetrics and Gynaecology Enugu State University of Science and Technology College of \\ Medicine/Teaching Hospital, Enugu, Nigeria \\ ${ }^{2}$ Department of Obstetrics and Gynaecology Enugu State University of Science and Technology Teaching \\ Hospital, Enugu, Nigeria \\ ${ }^{3}$ Department of Pharmacology and Therapeutics ESUT College of Medicine, Parklane GRA, Enugu, Nigeria
}

Corresponding Author: Ezenwaeze Malachy Nwaeze

\begin{abstract}
Gestational choriocarcinoma (GCC) is a highly malignant but rare tumour originating in the trophoblastic tissue. It is associated with high maternal morbidity and mortality especially when there is a delay in diagnosis and treatment. This is the only female malignant condition that is curable with chemotherapy following early treatment. The objective of this study was to retrospectively determining the incidence of choriocarcinoma, its clinical presentations, risk factors, the interval between the antecedent case and time of diagnosis, treatment options and outcome in ESUT-TH. The folders of patients treated for GCC over the period of the study served as source of data. Results showed that the incidence of GCC was $0.1 \%$ or 1 in 1731 deliveries. It further shows that GCC accounted for $0.2 \%$ of gynaecological admission in ESUTTH. Abnormal bleeding per vaginum and amenorrhoea were the commonest presenting symptoms discovered in this study, while other clinical presentations noted include; isolated vaginal nodule, ovarian mass and haemoptysis. Molar gestation and miscarriage were the risk factors discovered in this study, lungs were discovered to be the commonest site of metastasis. It is concluded that gestational choriocarcinoma is a rare malignancy in ESUT$\mathrm{TH}$, South-East Nigeria with minor case fatality.
\end{abstract}

Key words: Gestational, Choriocarcinoma, incidence

\section{INTRODUCTION}

Gestational choriocarcinoma is a highly malignant but rare tumor originating in the trophoblastic tissue [1]. Even though most cases of choriocarcinoma arise from malignant transformation of a complete molar pregnancy, it has been reported following term pregnancy, spontaneous miscarriage, and even after ectopic gestation [2]. Although, only $0.76-4 \%$ cases of choriocarcinoma develop in ectopic locations, they are usually more aggressive and associated with distant metastasis [3, 4]. It does not contain chorionic villi, but composed of sheets of both anaplastic cytotrophoblast and syncytiotrophoblast [5]. The tumour may erode into the uterine vessels, leading to vaginal bleeding or perforate myometrium causing intraperitoneal haemorrhage [6]. It is highly vascular and bleeds heavily; hence biopsy of the lesion is to be avoided [6]. It can develop anytime between 5 weeks to 15 years after gestation or even after menopause [7,8]. Approximately $80 \%$ of cases of choriocarcinoma have metastatic disease at the time of diagnosis, lungs being 
the commonest site $(80 \%)$, followed by vagina $(30 \%)$, then pelvis $(20 \%)$ and liver in $(10 \%)$ of cases. Metastasis to the brain occurs in $3-28 \%$ of patients [9]. The clinical presentation especially with symptoms from distant metastasis varies and can pose a challenge in making diagnosis. However, the combination of gynaecological history and elevated hCG usually make the diagnosis clear to avoid biopsy which is associated with severe hemorrhage [10]. It is curable with early diagnosis and appropriate chemotherapy treatment $[11,12]$. It is also radiosensitive. Because of high morbidity and mortality associated with choriocarcinoma especially in late presentation with its attendant complications, this study aims at unraveling the incidence of choriocarcinoma, its risk factors, clinical presentations, treatment options and outcome in Enugu State University of Science and Technology Teaching Hospital (ESUT-TH).

\section{METHODOLOGY}

This is a 7-year retrospective analysis of patients managed for choriocarcinoma at Enugu State University of Science and Technology Teaching Hospital, Enugu, Nigeria from 1st January, 2012 to $31^{\text {st }}$ December, 2018. The gynaecology ward and theatre registers were used to identify the folder numbers of patients treated for choriocarcinoma over the period of study. This helped access to the patient folders and the following variables of each patient analysed; age at presentation, marital status, occupation, parity, clinical presentation, risk factors, duration of risk factors before diagnosis, stage at presentation, treatment options, complications and outcome. Clinical presentation was defined as symptoms at presentation, physical examination findings and findings from diagnostic studies. Case fatality was considered if the condition causing death was attributable to choriocarcinoma or its complication.

\section{Statistical analysis}

Data analyses were done with the statistical package for social sciences (SPSS) and results were presented in tables and charts. Percentage and frequency were determined, Chi- square test was used to determine test of association ( $\mathrm{P}$ - value of significance set at 0.05 )

\section{RESULTS}

Table 1: Socio- demographic characteristics of the patients

\begin{tabular}{|l|c|c|}
\hline $\begin{array}{c}\text { Socio-demographic } \\
\text { characteristics }\end{array}$ & $\begin{array}{c}\text { Frequency } \\
\text { (n) }\end{array}$ & $\begin{array}{c}\text { Percentage } \\
(\%)\end{array}$ \\
\hline Age Groups(Years) & & 67 \\
\hline $28-37$ & 0 & 0 \\
\hline $38-47$ & 2 & 33 \\
\hline $48-57$ & & 100 \\
\hline Marital Status & 6 & 0 \\
\hline Yes & 0 & 0 \\
\hline No & & 17 \\
\hline Occupation & 0 & 33 \\
\hline Student/apprentice & 1 & 50 \\
\hline Farmer & 0 & 0 \\
\hline Unemployed & 2 & \\
\hline Business & 3 & 33 \\
\hline Civil servant & 0 & 17 \\
\hline Others (specify) & & 33 \\
\hline Education & 2 & 17 \\
\hline Primary education & 1 & 0 \\
\hline Secondary education & 2 & \\
\hline Tertiary education & 1 & \\
\hline No formal education & & \\
\hline Parity & 0 & \\
\hline $0-1$ & 3 & \\
\hline $2-3$ & & \\
\hline $4-5$ & & \\
\hline $6-7$ & & \\
\hline $8-9$ & & \\
\hline
\end{tabular}

A total of 7 cases of choriocarcinoma were diagnosed and treated over the 7-year period of study in ESUTTH, Parklane, Enugu. A retrieval rate of $100 \%$ was recorded as all the case files were retrieved from the medical record. However, one case file was devoid of complete record. A total of 12,120 deliveries and 3532 gynaecology admissions were recorded during the period of study, making the incidence of choriocarcinoma to be $0.1 \%$ or 1 in 1731 . It equally accounted for $0.2 \%$ of gynaecology admissions in ESUT-TH.

Table 1 shows the sociodemographic data of the patients. Their age ranged between 28 to 57 , mean $\left(42.5+_{-} 0.2\right)$ years, with patient between the age range of 28-37 being the highest (67\%).

Farming, trading, and civil service work were noted to be the occupation of the 
patients under study, civil service work being the majority $(50 \%)$ of patient' $s$ occupation. Patients with primary and tertiary levels of Education were highest in number, 2 each (33\% each) while those with secondary and no level of education lowest, 1 each (17\% each). All the patients managed for choriocarcinoma during the 7-year period were multiparous. The duration of time between the antecedent case and diagnosis of choriocarcinoma ranged between 5 weeks to 2 years.

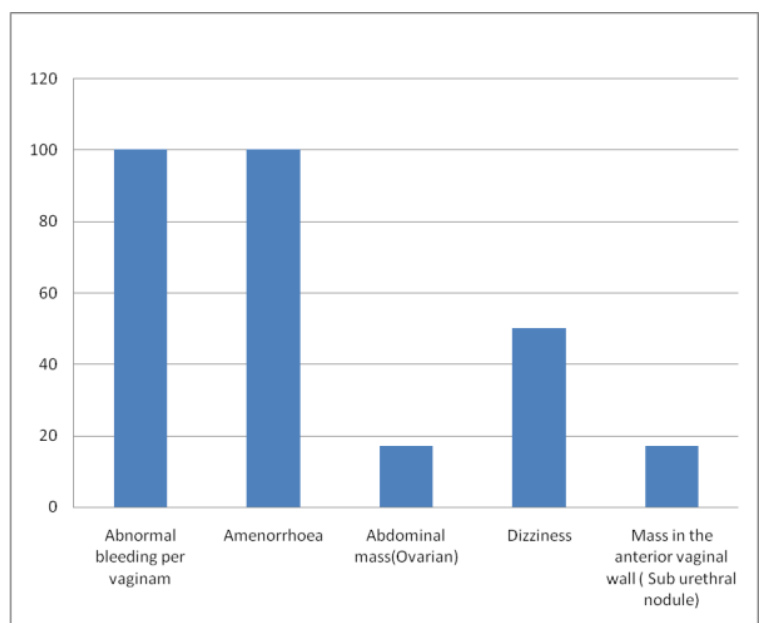

Fig 1: Bar Chart showing the clinical presentation of patients

The clinical presentation of patients managed for choriocarcinoma over the period of 7 years in ESUT-TH is depicted in the bar chart, fig 1 ranging from abnormal bleeding per vaginum, amenorrhoea, abdominal (ovarian) mass, dizziness, to mass in the anterior vaginal wall ( Sub urethral nodule). Abnormal bleeding per vaginum and amenorrhoea (100\% each) being the commonest presenting symptoms, followed by dizziness, while the least presenting symptoms were abdominal (ovarian) mass and mass in the anterior vaginal wall (Sub urethral nodule) $17 \%$ each. The risk factors associated with choriocarcinoma as seen in the study were antecedent molar pregnancy in $4(67 \%)$ patients and miscarriage in $2(33 \%)$ patients.

Options of treatment were informed by the stage and prognostic score of patients at the time of diagnosis depicted in the bar chart, fig 2. All the patients received chemotherapy. $4(66.7 \%)$ patients received single agent methotrexate chemotherapy, 1 $(16.7 \%)$ patient received combined chemotherapy of ethopoxide, methotrexate, actinomycin D, cyclophosphomide and oncovin regimen, while another 1(16.7\%) patient had combination chemotherapy as above as well as total abdominal hysterectomy. Out of the 4 patients that received single agent chemotherapy, 3 had stage 1 disease while 1 had stage 2 disease but of low risk prognostic score $(<7)$. The 2 patients that received combination chemotherapy had stage 3 disease with high risk prognostic scores $(>7)$. Out of these 2 , one of them that falls between the parity range of 8-9 above who was not desirous of further pregnancy had total abdominal hysterectomy as well.

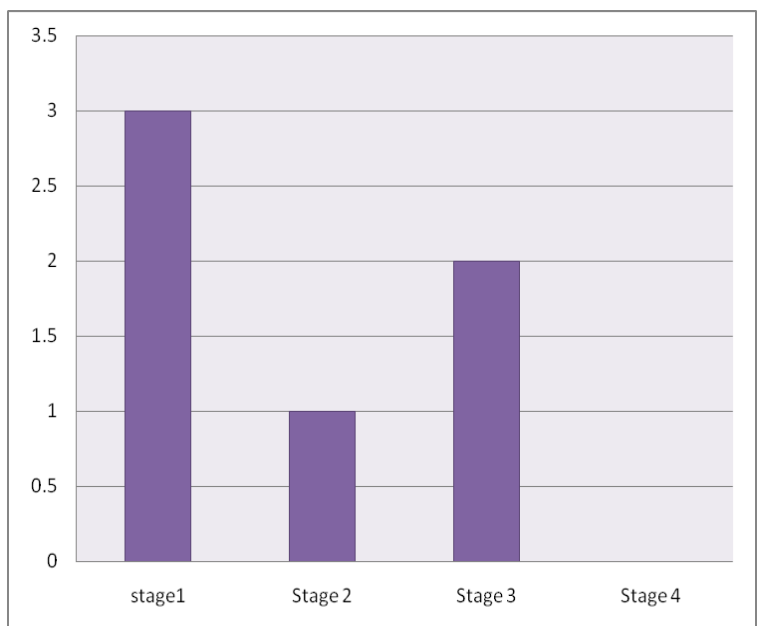

Fig 2: Bar Chart showing the stage of patient at diagnosis

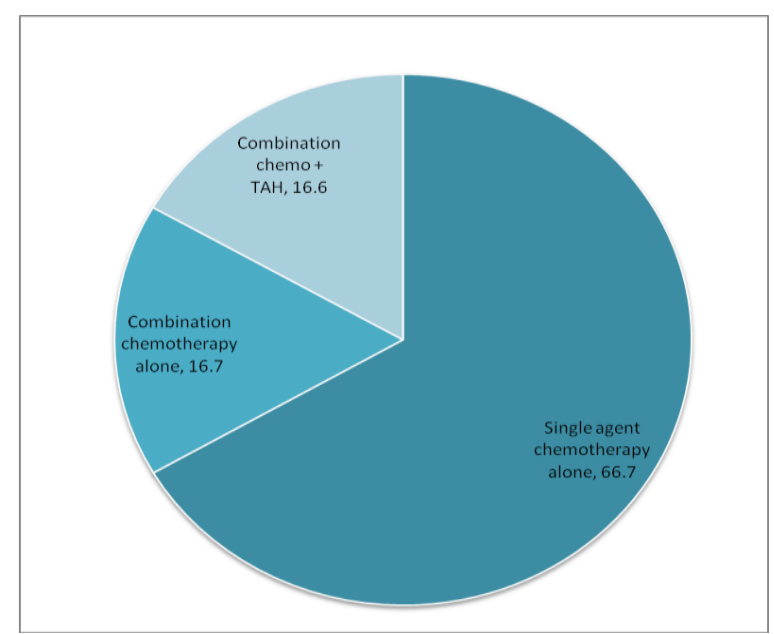

Fig 3: Pie Chart showing the treatment options offered to the patients 


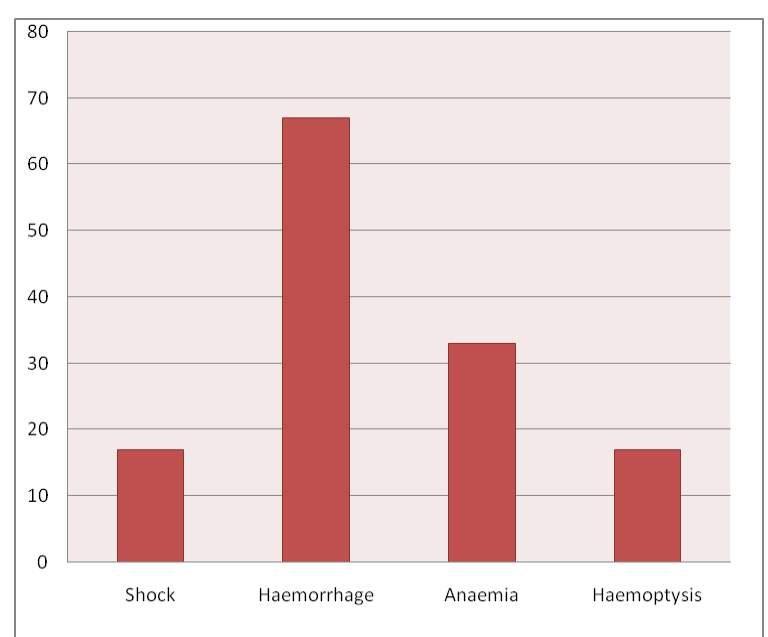

Fig 4: Bar Chart showing complications observed

Fig 4 shows that shock, haemorrhage, anaemia and haemoptysis were the complications observed in patient that were managed for choriocarcinoma. Patients with haemorrhage $(67 \%)$ had the highest number of complication, the next being patients with anaemia $(33 \%)$, shock and haemoptysis were the least complications noted, $(17 \%)$ each. 1 case of fatality was recorded, this was seen in the patient with highest parity [para 8], who also presented late, at stage 3 disease and was lost to follow-up. The other patients had good remission following chemotherapy.

\section{DISCUSSION}

The incidence of gestational choriocarcinoma observed in this study was $0.1 \%$ or 1 in 1,731 deliveries. This was lower than the incidence of $4.3 \%$ reported in an earlier study done in Enugu South-East Nigeria [13] and 1 in 1039 reported in North-West Nigeria [14]. The lower incidence noted could be due to that our centre is not just a referral centre, being a Teaching Hospital, but a centre that receives the bulk of patients that would have ordinarily presented to secondary and other peripheral centres because of its central location and as that, offers better patient management thereby limiting cases that would have progressed to choriocarcinoma. However, the finding was higher than the incidence of 1 in 40,000 documented in United State of America [15], although Cultural and environmental factors may have played out Abnormal bleeding per vaginum and amenorrhoea being the commonest presenting symptoms observed in this study was similar with the findings in the literature [12]. Other clinical presentations documented in literature as found in this study include; isolated vaginal nodule [16], ovarian mass and haemoptysis. Haemoptysis was from lung metastasis and lung metastasis has been documented to be the commonest site of metastasis [11].

Molar gestation and abortion were the risk factors observed in this study which was similar to findings in previous studies $[17,18,19]$. Although, chemotherapy is the treatment of choice which all the patients in this study received, massive life-threatening vaginal bleeding may warrant surgery especially in the form of hysterectomy even in reproductive age women [20]. One patient $(17 \%)$ with metastatic disease, who also presented with anaemia due to blood loss in addition had total abdominal hysterectomy, which is an option for older women not desirous of more pregnancy and even for women with molar pregnancy but with high propensity to develop malignant condition [21,22]. One case of death (17\%) was recorded, while all the other patients had good remission with chemotherapy. The fatality recorded could be attributed to worst stage from late presentation complicated with anaemia, high parity as well as lost to follow-up. The case fatality of $17 \%$ discovered in this study was lower than the observation from earlier studies in Enugu where the case fatality was as high as $53.3 \%$ [23]. The finding varies with other studies where there were no recorded maternal deaths [21,24]. The lower case fatality discovered could be attributed to the good outcome of treatment following early presentation and prompt treatment of the affected patients, which is also similar with observation in literature $[11,12]$.

\section{CONCLUSSION}

It is concluded that Gestational choriocarcinoma is a very rare malignancy in ESUT-TH, South-East Nigeria with 
incidence of 1 in 1,731 deliveries. Abnormal vaginal bleeding is a common presenting symptom, with haemorrhage, shock and anaemia being the commonest complications. Appropriate chemotherapy following early presentation is likely to improve the prognosis. Histopathological study of post-abortal product of conception, surveillance of those with molar pregnancy and high index of suspicion are essential in identifying at risk patients. Early presentation, diagnosis, treatment, adequate patient counselling are needed to avert high morbidity and mortality associated with choriocarcinoma.

Data Availability: All the necessary data are included in the manuscript

Conflicting Interests: The authors declare that they have no conflicting interests.

Funding: This research was completely sponsored by the authors. There was no external funding to the research

Authors' Contributions: All authors were involved in the conception, design, data collection, analysis and final draft of the manuscript.

Acknowledgment: The authors are grateful to the Nursing Staff and Medical record Officers of the Hospital for appropriate registration of managed cases and record keeping respectively. The authors also want to gratify the House Officers that helped in patient' $s$ folders lifting and review.

\section{Ethical Approval: Approved}

\section{REFERENCES}

1. Mangla M, Singla D, kaur H, Sharma S. Unusual cinical presentations of choriocarcinoma: A systematic review of case reports. Taiwan J Obstet Gynecol.2017 Feb;56(1):1-8

2. Meddeb S, Rhim MS, Zarrouk W, Bibi M, Yacoubi MT, Khairi H. Unusual gestational choriocarcinoma arising in an interstitial pregnancy. Int J Surg Case Rep 2014; 5:787e8.
3. Chen MJ, Yang JH, Lin MC, Ho HN, Yang YS. An unusual gestational choriocarcinoma occurring primarily in the surface of subserous leiomyoma. BJOG 2004; 111:188e90.

4. Salleh S, Arthrur I. Persistent peritoneal trophoblastic implantation following salpingotomy, salpingectomy and Methotrexate for ectopic pregnancy. Gynecol Surg 2005; 2:195e6.

5. Aghajanian P. Gestational Trophoblastic disease. In:Decherney AH, Nathan L,Godwin TM, Laufer N,editors. Current diagnosis Treatment in Obstetrics and Gynaecology. $10^{\text {th }}$ Ed. New York: Mc Craw Hill Medical Divisionb;2007.P.885-95

6. Kwawukume EY, Emuveyan E E, Comprehensive Gynaecology in the tropics; 2005 498-511

7. Hassadia A, Kew FM, Tidy JA, Wells M, Hancock BW. Ectopic gestational trophoblastic disease: a case series review. J Reprod Med 2012; 57:297e300.

8. Soper JT, Mutch DG, Schink JC. American college of Obstetricians and Gynaecologists diagnosis and treatment of gestational trophoblastic disease; ACOG practice bulletein no. 53. Gynecol Oncol 2004; 93:575e85. M. Mangla et al./Taiwanese Journal of Obstetrics \& Gynecology 56 (2017) 1 e86

9. Berkowitz RS, Goldstein DP. Gestational Trophoblastic Disease. In: Berek J, editor. Berek \&Novak's Gynecology. Philadelphia: Lippincott Williams \& Wilkins; 2007. p. $1581 \mathrm{e} 603$.

10. Savage P. Secki M. Trophoblastic disease. In: Edmund KD, editor, Dewhurst' $\mathrm{s}$ Textbook of Obstetrics and Gynaecology. $7^{\text {th }}$ Ed.UK:Black well publishing, Inc.2007. p.117-24

11. Feng F,Xiang Y. Surgical management of chemotherapy- resistant gestational trophoblastic neoplasia. Expert Rev AnticancerTher.2010;10(1):71-80.d0i.1586/ era.09.169

12. Lurain JR, Singh DK, Schink JC. Role of surgery in the management of high-risk gestational trophoblastic neoplasia. J Reprod Med.2006;51(10):773-6

13. Ugwu EO,Iferikigwe ES, Okeke TC, Ugwu AO, Okezie OA,Agu PU. Pattern of gynaecological cancers in University of Nigeria, Teaching Hospital, Enugu. Niger J Med.2011 Apr-June;20(2);266-9 
Nweze Sylvester Onuegbunam et.al. Decreasing incidence of gestational choriocarcinoma in Enugu State University of Science and Technology Teaching Hospital, South-East Nigeria: a 7-year review

14. Mayun AA, Rafindadi AH, Shehu MS. Choriocarcinoma in Northwestern Nigeria: a histopathological review. Niger Postgraduate Med J.2012;19(4):215-8

15. Smith HO, Kohorn E, Cole LA. Cole LA. Choriocarcinoma and gestational trophoblastic disease. Obstet Gynecol Clin North AM 2005;32:661.PMID:16310678.

16. Samantaray S, Rout N, Kakkar S, Pattanayak L. Choriocarcinoma presenting as a vaginal nodule: a rare presentation diagnosed by fine needle aspiration cytology. Acta Cytol 2009;53:364e5.

17. Ee,niola OA, Mbayoje P, Ogunniyi SO. Hydatidiform mole in Ile-If, Nigeria: A review. J Obstet Gynaecol 2001;21:405-7

18. Egwuatu VE, Ozumba BC. Observation on molar pregnancy in Enugu, Nigeria. Int $\mathbf{J}$ Gynaecol Obstet 1989;29:219-25

19. Atta EB. Hydatidiform mole.in: Human pathology. $1^{\text {st }}$ Ed.Ibadan: Ibadan University press;2000.p.519-22

20. Topuz S, Iyibozkurt C, Mete O, Akhan S, Saliho glu Y, Bengisu E, et al. Life-d
21. Agbola A.Trophoblastic Tumours.Testbook of Obstetrics and Gynaecology for medical students. $2^{\text {nd }}$ Ed.Ibadan,Nigeria d

22. Ocheke AN, Musa J, Uamai AO. Hydatidiform mole in Jos, Nigeria. Niger Med J 2011;52-223-6 D

23. Dim CC, Ezegwu HU. Choriocarcinoma in Enugu, South east Nigeria: a need for a shift from mortality to survival. Niger J Med. 2013;22(3):252-6 d

24. Page RD, Kudella AP, Freedman RS, Kavanagh RJ. Gestational trophoblastic tumours: a comparative review, Medical Oncology: 2005.8 ${ }^{\text {th }}$ Ed. Oncology. $d$

How to cite this article: Nwaeze SO, Ezenwaeze $\mathrm{MN}$, Igwe SA. Decreasing incidence of gestational choriocarcinoma in Enugu State University of Science and Technology Teaching Hospital, South-East Nigeria: a 7-year review. International Journal of Research and Review. 2021; 8(5): 7-12. DOI: https://doi.org/ 10.52403/ijrr.20210502 